\title{
Short communication: Use of lameness scoring to genetically improve claw health in Austrian Fleckvieh, Brown Swiss, and Holstein cattle
}

\author{
A. Köck, ${ }^{1 *}$ B. Fuerst-Waltll, ${ }^{2}$ J. Kofler, ${ }^{3}$ J. Burgstaller, ${ }^{3}$ F. Steininger, ${ }^{1}$ C. Fuerst, ${ }^{1}$ and C. Egger-Danner ${ }^{1}$ \\ ${ }^{1}$ ZuchtData EDV-Dienstleistungen GmbH, Dresdner Str. 89/19, 1200 Vienna, Austria \\ ${ }^{2}$ University of Natural Resources and Life Sciences Vienna (BOKU), Department of Sustainable Agricultural Systems, \\ Division of Livestock Sciences, Gregor-Mendel-Str. 33, 1180 Vienna, Austria \\ ${ }^{3}$ University of Veterinary Medicine Vienna, University Clinic for Ruminants, Veterinärplatz 1, 1210 Vienna, Austria
}

\section{ABSTRACT}

The specific objective of this study was to evaluate the use of lameness scoring to genetically improve claw health in Austrian Fleckvieh, Brown Swiss, and Holstein cows based on data from the "Efficient Cow" project. In 2014, a 1-yr data collection was carried out. Data from 6,519 cows kept on 161 farms were recorded. At each time of milk recording, lameness scores were assessed by trained staff of the milk recording organizations. Hoof trimming on these farms was documented and recorded as well. Veterinarian diagnoses and culling due to foot and leg problems from these farms were available from the routine recording system. As repeated lameness records per cow and lactation were available, an overall lactation lameness score was calculated. Estimated heritabilities for lameness were 0.11, 0.05, and 0.09 for Fleckvieh, Brown Swiss, and Holstein, respectively; however, only heritability estimates for Fleckvieh were significantly different from zero. Breeding values for lameness were obtained, reversed in sign, and cows were ranked according to their breeding value. A low breeding value for lameness resistance (the bottom $10 \%$ of the cows) was associated with a significantly higher frequency of trimmed cows, which indicates that the cows selected by the farmer to be trimmed are not completely random. Additionally, a high breeding value for lameness resistance (the top $10 \%$ of the cows) was associated with lower frequencies of claw diseases recorded at trimming, claw and leg diagnoses, and culling due to foot and leg problems, which highlights the usefulness of lameness scoring for genetic improvement of claw health. Overall, selecting for a better lameness score has the potential to reduce claw diseases, especially the frequency of severe claw diseases that lead to culling.

Received June 27, 2018.

Accepted November 4, 2018.

*Corresponding author: koeck@zuchtdata.at
Key words: lameness score, hoof trimming, veterinarian diagnosis, claw health

\section{Short Communication}

Claw diseases are a serious welfare problem and cause significant economic losses in dairy cattle. Lameness is often used as an indicator of claw diseases. It is a painful condition and a common reason for involuntary culling, reduced milk production, and reproductive problems (Green et al., 2002; Garbarino et al., 2004; Burgstaller et al., 2017).

Until now only foot and leg conformation traits are considered in the Austrian dairy cattle breeding program. Lameness or locomotion is not routinely recorded. A survey among Austrian farmers revealed that, among other traits (e.g., efficiency and metabolism), further claw health traits need to be considered (Steininger et al., 2012). To get insight into these new required trait complexes, the "Efficient Cow" project was started in Austria in 2012 with a 1-yr data collection in 2014. Novel phenotypes, including lameness and hoof trimmer data, have been recorded on 161 farms and 6,105 cows in Austria covering the breeds Fleckvieh (Simmental), Brown Swiss, and Holstein. Farms were selected to cover diverse production environments in Austria, ranging from mountainous regions to intensive farms in climatically favorable regions. Despite this, the average herd size with 32.7 cows was approximately twice as high as the Austrian average (Ledinek et al., 2018). As reported by Ledinek et al. (2018) the project farms represented an above-average production level of Austria with mostly grass silage $(39.5 \%$ of the farms) and maize silage (27.1\% of the farms) based diets. The specific objective of this study was to evaluate if lameness scoring is effective to genetically improve claw health in Austrian Fleckvieh, Brown Swiss, and Holstein cows.

Lameness scores were available from the "Efficient Cow" project from January 2014 to December 2014. Lameness scoring was performed by specially trained 
milk recording technicians at each test-day (approximately every $5 \mathrm{wk}$ ) using the scoring system by Sprecher et al. (1997). The lameness scoring was mostly done after milking time. Repeated training sessions ensured the consistency of the lameness score assessment between and within observer by evaluating inter- and intra-observer variability.

For analyses, all cows that had at least one lameness scoring within the first $365 \mathrm{~d}$ after calving were considered. As repeated records per cow and lactation were available, an overall lactation lameness score was calculated and considered:

- 1 = always 1 (not lame),

- 2 = at least one lameness score of 2 and lower (mildly lame),

- 3 = at least one lameness score of 3 and lower (moderately lame),

- 4 = at least one lameness score of 4 and lower (lame), and

- 5 = at least one lameness score of 5 and lower (severely lame).

Hoof trimming data were also available from the "Efficient Cow" project and were carried out mainly by professional hoof trimmers. A standardized Austrian-wide hoof trimming protocol was used. The Claw Health Atlas of the International Committee for Animal Recording was not available at that time. Hoof trimmers recorded both the diseased cows and the healthy cows that were trimmed. As not all cows were trimmed during the study period, a $1 / 0$ trimming status trait was defined based on whether or not the cow was trimmed within the first $365 \mathrm{~d}$ after calving. Each claw disease detected at hoof trimming was defined as binary trait $(1 / 0)$ based on whether or not the cow had at least one hoof trimming record for heel horn erosion, digital dermatitis, double sole, sole hemorrhage, sole ulcer, white line disease, limax, or any claw disease within the first $365 \mathrm{~d}$ after calving.

Veterinary diagnoses and culling data are routinely recorded and were available for all herds participating in the "Efficient Cow" project. The trait claw diagnoses was defined as binary trait $(1 / 0)$ based on whether or not the cow had at least one diagnosis for panaritium, digital dermatitis, sole ulcer, or laminitis within the first $365 \mathrm{~d}$ after calving. The trait leg diagnoses was defined as a binary trait $(1 / 0)$ based on whether or not the cow had at least one diagnosis for fractures, dislocations, other limb injuries, diseases of muscles and tendons, spastic paresis, paralysis, peritarsitis, and diseases of the musculoskeletal system within the first $365 \mathrm{~d}$ after calving. The trait culling due to foot and leg problems was defined as a binary trait $(1 / 0)$ based on whether or not the cow was culled due to foot and leg problems within the first $365 \mathrm{~d}$ after calving.

Analyses were carried out for Fleckvieh, Brown Swiss, and Holstein cows with a maximum foreign gene proportion of $25 \%$ from another breed from all parities. After edits, in total 4,728 records for Fleckvieh $(3,205$ cows from 104 herds), 2,050 records for Brown Swiss (1,451 cows from 52 herds), and 1,482 records for Holstein (1,091 cows from 58 herds) were used for analyses. A summary of statistics of the analyzed data sets is given in Table 1. Animal pedigree files were generated for each breed by tracing back as many generations as possible for cows with records. The total number of animals within each pedigree was $34,324,15,320$, and 14,743 for Fleckvieh, Brown Swiss, and Holstein, respectively.

Heritabilities were estimated for lameness score with a univariate linear animal model using the average information-restricted maximum likelihood procedure in the DMU package (Madsen and Jensen, 2008). The following model was applied:

$$
\mathbf{y}=\mathbf{X} \boldsymbol{\beta}+\mathbf{Z}_{\mathrm{pe}} \mathbf{p e}+\mathbf{Z}_{\mathrm{a}} \mathbf{a}+\mathbf{e},
$$

where $\mathbf{y}$ is a vector of observations for lameness score; $\boldsymbol{\beta}$ is a vector of systematic effects, including fixed effects of herd $(104,52$, and 58 classes for Fleckvieh, Brown Swiss, and Holstein, respectively), year-season of calving (9 classes), parity (3 classes), and classifier (27, 19, and 25 classes for Fleckvieh, Brown Swiss, and Holstein, respectively); pe is a vector of random permanent environmental effects; $\mathbf{a}$ is a vector of random animal additive genetic effects; $\mathbf{e}$ is a vector of random residuals; and $\mathbf{X}, \mathbf{Z}_{\mathrm{pe}}$, and $\mathbf{Z}_{\mathrm{a}}$ are the corresponding incidence matrices. Seasons were formed by combining 3 consecutive months (January-March, April-June, July-September, and October-December). Parity had 3 classes with 1, 2, and $3+$.

Breeding values for lameness were obtained from the univariate analyses above. Breeding values for lameness were reversed in sign; thus, higher breeding values are desirable. Cows were ranked according to their EBV. The frequencies of trimmed cows, claw diseases at trimming, claw diagnoses, and culling due to foot and leg problems were compared from the bottom and top 10\% of cows. Differences between group means were tested by a 2 -sample $t$-test (version 9.4, SAS Institute Inc., Cary, NC).

Table 1 shows the frequency of cows with different severity of lameness. The percentage of nonlame cows was highest in Brown Swiss (62.7\%) and lowest in Holstein $(49.6 \%)$. A higher percentage of nonlame cows 
Table 1. Frequency (\%) of records with different severity of lameness and mean values for trimming status, claw diseases, claw diagnoses, and culling due to foot and leg problems for Fleckvieh, Brown Swiss, and Holstein

\begin{tabular}{|c|c|c|c|}
\hline Trait & $\begin{array}{l}\text { Fleckvieh } \\
(\mathrm{n}=4,728)\end{array}$ & $\begin{array}{l}\text { Brown Swiss } \\
(\mathrm{n}=2,050)\end{array}$ & $\begin{array}{c}\text { Holstein } \\
(\mathrm{n}=1,482)\end{array}$ \\
\hline \multicolumn{4}{|l|}{ Lameness score } \\
\hline Not lame, $\%$ & 60.1 & 62.7 & 49.6 \\
\hline Mildly lame, $\%$ & 24.0 & 22.1 & 30.8 \\
\hline Moderately lame, $\%$ & 9.2 & 9.9 & 13.1 \\
\hline Lame, \% & 5.5 & 4.0 & 5.0 \\
\hline Severely lame, \% & 1.2 & 1.3 & 1.5 \\
\hline \multicolumn{4}{|l|}{ Hoof trimming data } \\
\hline Trimming status, \% & 49.7 & 52.6 & 49.9 \\
\hline Any claw disease, ${ }^{1} \%$ & 50.0 & 37.3 & 54.5 \\
\hline Heel horn erosion, ${ }^{1} \%$ & 13.0 & 5.5 & 11.1 \\
\hline Digital dermatitis, ${ }^{1} \%$ & 2.9 & 8.6 & 24.9 \\
\hline Double sole, ${ }^{1} \%$ & 10.0 & 5.9 & 6.8 \\
\hline Sole hemorrhage, ${ }^{1} \%$ & 7.2 & 2.7 & 5.7 \\
\hline Sole ulcer, ${ }^{1} \%$ & 10.3 & 12.7 & 18.7 \\
\hline White line disease, ${ }^{1} \%$ & 23.6 & 11.1 & 10.0 \\
\hline $\operatorname{Limax},{ }^{1} \%$ & 2.6 & 4.4 & 7.8 \\
\hline \multicolumn{4}{|l|}{ Veterinarian diagnosis } \\
\hline Claw diagnoses, $\%$ & 2.8 & 3.2 & 3.3 \\
\hline Leg diagnoses, \% & 0.8 & 0.6 & 0.8 \\
\hline \multicolumn{4}{|l|}{ Culling reason } \\
\hline Culling due to foot and leg problems, $\%$ & 1.1 & 1.5 & 1.7 \\
\hline
\end{tabular}

${ }^{1}$ Because not all cows were trimmed during the study period, the number of records for any claw disease recorded at trimming was 2,348 for Fleckvieh, 1,079 for Brown Swiss, and 739 for Holstein.

was reported in a previous Austrian study by Kofler et al. (2013). They reported that, based on 679 cows from 15 Austrian farms, on average $71.9 \%$ (maximum $95.0 \%$, minimum $21.1 \%$ ) and $72.9 \%$ (maximum $100.0 \%$, minimum $12.6 \%$ ) of the cows were not lame at visit 1 and 2 , respectively.

Between 50 to $53 \%$ of all cows were trimmed during the study period (Table 1). From the cows that were trimmed, 50, 37, and 55\% of Fleckvieh, Brown Swiss, and Holstein cows, respectively, had at least one claw disease. The most frequent claw diseases were white line disease in Fleckvieh (23.6\%), sole ulcer and white line disease in Brown Swiss (12.7 and 11.1\%, respectively), and digital dermatitis in Holstein (24.9\%; Table 1). In a previous study, based on hoof trimming data of 1,029 cows from 45 Austrian farms, $28 \%$ of the cows had at least one claw disease at trimming. The main claw diseases were laminitis (16.1\%) and sole ulcer (9.2\%; Maier, 2009).

In comparison, the frequency of claw diseases recorded by veterinarians is significantly lower, as a veterinarian is only needed in more severe cases. The frequencies of cows with claw diagnoses were $2.8 \%$ for Fleckvieh, $3.2 \%$ for Brown Swiss, and 3.3\% for Holstein (Table 1 ). Frequencies of leg diagnoses were below $1 \%$ in all 3 breeds. Frequencies of culling due to foot and leg problems were 1.1, 1.5, and 1.7\% for Fleckvieh, Brown Swiss, and Holstein cows, respectively.
Estimated heritabilities for lameness were low $(0.11$, 0.05, and 0.09 for Fleckvieh, Brown Swiss, and Holstein, respectively; Table 2); however, only heritability estimates for Fleckvieh were significantly different from zero. Although Weber et al. (2013) used a slightly different trait definition for lameness, namely as a binary trait $(0=$ lameness score of 1 or $2,1=$ lameness score of $\geq 3$ ), a similar heritability of 0.08 was found based on a linear model.

A low EBV for lameness resistance (the bottom $10 \%$ of the cows) was associated with a significantly higher frequency of trimmed cows in all 3 breeds (Table 3), which indicates that the cows selected by the farmer to be trimmed is not completely random. Some cows need to be trimmed more often than others and van der Spek et al. (2013) showed that the need for trimming, or trimming status, is a heritable trait with a heritability estimate of 0.09. A high need for trimming the claws of cows is unfavorable and therefore trimming status is an interesting trait to include in genetic evaluation.

Table 2. Heritabilities and SE for lameness score for Fleckvieh, Brown Swiss, and Holstein

\begin{tabular}{lcc}
\hline Breed & Heritability & SE \\
\hline Fleckvieh & 0.111 & 0.033 \\
Brown Swiss & 0.054 & 0.035 \\
Holstein & 0.089 & 0.055 \\
\hline
\end{tabular}


Table 3. Top and bottom 10\% cows ranked by their EBV for lameness resistance and their means for trimming status, claw diseases, claw diagnoses, and culling due to foot and leg problems for Fleckvieh, Brown Swiss, and Holstein

\begin{tabular}{|c|c|c|c|c|c|c|c|c|c|}
\hline \multirow[b]{2}{*}{ Trait } & \multicolumn{3}{|c|}{ Fleckvieh } & \multicolumn{3}{|c|}{ Brown Swiss } & \multicolumn{3}{|c|}{ Holstein } \\
\hline & Bottom & Top & $P$-value ${ }^{1}$ & Bottom & Top & $P$-value ${ }^{1}$ & Bottom & Top & $P$-value ${ }^{1}$ \\
\hline Trimming status, $\%$ & 60.5 & 47.9 & $* * *$ & 64.0 & 44.1 & $* * *$ & 62.6 & 49.7 & * \\
\hline Any claw disease, $\%$ & 65.6 & 36.8 & $* * *$ & 65.2 & 18.1 & $* * *$ & 66.3 & 30.8 & $* * *$ \\
\hline Heel horn erosion, \% & 13.3 & 9.4 & & 7.4 & 1.1 & $*$ & 10.9 & 7.7 & \\
\hline Digital dermatitis, \% & 2.8 & 2.1 & & 17.8 & 4.3 & $* *$ & 29.3 & 14.1 & $*$ \\
\hline Sole ulcer, \% & 19.3 & 3.8 & $* * *$ & 31.1 & 2.1 & $* * *$ & 25.0 & 6.4 & ** \\
\hline White line disease, \% & 28.1 & 18.8 & $*$ & 20.0 & 6.4 & $* *$ & 16.3 & 2.6 & ** \\
\hline Limax, $\%$ & 6.3 & 0.9 & $* *$ & 8.1 & 1.1 & $*$ & 14.1 & 2.6 & $* *$ \\
\hline \multicolumn{10}{|l|}{ Veterinarian diagnosis } \\
\hline Claw diagnosis, $\%$ & 5.6 & 2.5 & $*$ & 5.2 & 3.3 & & 4.8 & 1.9 & \\
\hline Leg diagnosis, $\%$ & 1.9 & 0.2 & $* *$ & 1.9 & 0.5 & & 0.7 & 0.6 & \\
\hline \multicolumn{10}{|l|}{ Culling reason } \\
\hline
\end{tabular}

${ }^{1}$ Differences between group means were tested by a 2 -sample $t$-test.

${ }^{*} P<0.05 ;{ }^{* *} P<0.01 ;{ }^{* * *} P<0.001$.

In agreement, Malchiodi et al. (2016) showed that the trimming status had moderate negative correlations with locomotion and the overall score for feet and legs. This suggests that the pre-selection process, in which cows are presented to the hoof trimmer, is associated with mobility and the foot and leg conformation of the cow.

Additionally, a high EBV for lameness resistance (the top $10 \%$ of the cows) was associated with lower frequencies of claw diseases at trimming (significant in all 3 breeds) and claw and leg diagnoses (significant only in Fleckvieh). Culling due to foot and leg problems in cows with a high EBV for lameness was near zero in all 3 breeds (Table 3). Based on the same data set, however, with slightly different trait definitions, Egger-Danner et al. (2017) consistently estimated positive genetic correlations between the claw health traits. Due to partly rather high standard errors for genetic correlations, analyses for the genetic relationships between hoof trimming data and diseases will be repeated after receiving a larger data set on hoof trimming from another project. Positive genetic correlations between lameness/locomotion and claw diseases were found in previous studies. Boelling et al. (2008) found a genetic correlation of 0.79 between claw diseases recorded by hoof trimmers and locomotion score. Similarly, Weber et al. (2013) reported genetic correlations from 0.60 to 0.72 (threshold model) and from 0.94 to 0.95 (linear model) between lameness and claw and leg diseases.

Overall, the results indicate the usefulness of lameness scoring for genetic improvement of claw health. Selecting for a better lameness score has the potential to reduce claw diseases, especially the frequency of severe claw diseases that lead to culling.

\section{ACKNOWLEDGMENTS}

The study was supported by the project "Efficient Cow" funded by the Austrian Federal Ministry of Sustainability and Tourism (Vienna); the Federations of Austrian Fleckvieh (Zwettl), Brown-Swiss (Innsbruck), and Holstein (Leoben); the Federation of Austrian Cattle Breeders (Vienna); and the COMET (Competence Centers for Excellent Technologies) K-Project "ADDA-Advancement of Dairying in Austria" (Vienna). The latter project was supported by BMVIT (Austrian Ministry for Transport, Innovation and Technology), BMWFW (Federal Ministry of Science, Research and Economy), the province of Lower Austria, and the city of Vienna in the framework of COMET. The COMET program is handled by the FFG (Austrian Research Promotion Agency).

\section{REFERENCES}

Boelling, D., A. Fogh, and U. S. Nielsen. 2008. Claw trimming records and locomotion can improve selection for feet and legs. Page 211 in Proc. 59th Annu. Mtg. European Assoc. Anim. Prod., Vilnius, Lithuania. Wageningen Academic Publishers, Wageningen, the Netherlands.

Burgstaller, J., C. Egger-Danner, S. Guggenbichler, B. Fürst-Waltl, F Steininger, and J. Kofler. 2017. The influence of lameness and claw disorders on fertility parameters in Austrian dairy cows. Pages 345-346 in 19th International Symposium and 11th International Conference of Lameness in Ruminants, Munich, Germany. 
Egger-Danner, C., A. Köck, J. Kofler, J. Burgstaller, F. Steininger, C. Fürst, and B. Fürst-Waltl. 2017. Evaluation of different data sources for genetic improvement of claw health in Austrian Fleckvieh (Simmental) and Brown Swiss cattle. Page 294 in 19th International Symposium and 11th International Conference of Lameness in Ruminants, Munich, Germany.

Garbarino, E. J., J. A. Hernandez, J. K. Shearer, C. A. Risco, and W. W. Thatcher. 2004. Effect of lameness on ovarian activity in postpartum Holstein cows. J. Dairy Sci. 87:4123-4131.

Green, L. E., V. J. Hedges, Y. H. Schukken, R. W. Blowey, and A. J. Packington. 2002. The impact of clinical lameness on the milk yield of dairy cows. J. Dairy Sci. 85:2250-2256.

Kofler, J., R. Pesenhofer, G. Landl, I. Sommerfeld-Stur, and C. Peham. 2013. Langzeitkontrolle der Klauengesundheit von Milchkühen in 15 Herden mithilfe des Klauenmanagers und digitaler Kennzahlen. Tierarztl. Prax. 41:31-44.

Ledinek, M., L. Gruber, F. Steininger, K. Zottl, M. Royer, K. Krimberger, M. Mayerhofer, C. Egger-Danner, and B. Fürst-Waltl. 2018. Analysis of lactating cows in commercial Austrian dairy farms: Diet composition, and influence of genotype, parity and stage of lactation on nutrient intake, body weight and body condition score. Ital. J. Anim. Sci. https://doi.org/10.1080/1828051X .2018.1504632.

Madsen, P., and J. Jensen. 2008. An User's Guide to DMU. A package for analyzing multivariate mixed models. Version 6 , release 4.7 . Danish Institute of Agricultural Sciences, Tjele, Denmark.
Maier, M. 2009. Erfassung der Klauenveränderungen im Rahmen der Klauenpflege. Ergebnisse einer Pilotstudie sowie Optimierung und Standardisierung der Datenerfassung im Projekt "Gesundheitsmonitoring Rind" in Österreich. Master thesis. University of Natural Resources and Life Sciences, Vienna, Austria. Accessed Sep. 11, 2018. https://zidapps.boku.ac.at/abstracts/download.php ?dataset_id $=7428 \&$ property_id $=107$.

Malchiodi, F., A. M. Christen, D. F. Kelton, F. S. Schenkel, and F. Miglior. 2016. Genetic correlations of hoof lesions and trimming status with feet and leg conformation traits in Canadian Holsteins. J. Anim. Sci. 94(Suppl. 5):184. https://doi.org/10.2527/jam2016 -0380 .

Sprecher, D. J., D. E. Hostetler, and J. B. Kaneene. 1997. A lameness scoring system that uses posture and gait to predict dairy cattle reproductive performance. Theriogenology 47:1179-1187.

Steininger, F., B. Fuerst-Waltl, C. Pfeiffer, C. Fuerst, H. Schwarzenbacher, and C. Egger-Danner. 2012. Participatory development of breeding goals in Austrian dairy cattle. 20th International Symposium Animal Science Days, Kranjska gora, Acta Agriculturae Slovenica, Supplement 3:143-147.

van der Spek, D., J. A. M. van Arendonk, A. A. A. Vallée, and H. Bovenhuis. 2013. Genetic parameters for claw disorders and the effect of preselecting cows for trimming. J. Dairy Sci. 96:6070-6078.

Weber, A., E. Stamer, W. Junge, and G. Thaller. 2013. Genetic parameters for lameness and claw and leg diseases in dairy cattle. J. Dairy Sci. 96:3310-3318. 